\title{
Exercise testing and prognosis in adult cystic fibrosis
}

\author{
A J Moorcroft, M E Dodd, A K Webb
}

\begin{abstract}
Background - The assessment of prognosis is an important issue in cystic fibrosis. The prognostic value of exercise testing in comparison with other predictors of mortality was examined.

Methods - Ninety two adult patients with cystic fibrosis performed progressive maximal exercise tests and outcome was assessed at five years. The results of exercise testing were examined along with spirometric values, age, sex, body mass index (BMI), and sputum culture.
\end{abstract}

Results - Twenty two subjects died during the five year follow up period and 67 survived. Five subjects received a lung transplant and were excluded from the analysis. There were significant differences between those who survived and those who died: mean(SE) forced expiratory volume in one second $\left(\mathrm{FEV}_{1}\right) 68.9$ (2.7) versus $39.7(3.5) \%$ predicted, BMI 19.0 (0.3) versus $17.1(0.4)$ $\mathrm{kg} / \mathrm{m}^{2}$, peak oxygen uptake $\left(\dot{V}_{2}\right.$ peak) 66.6 (2.2) versus 53.7 (3.7)\% predicted, peak work rate (Wpeak) 89.4 (3.8) versus 71.2 (5.5)\% predicted, peak minute ventilation (VEEeak) 51.3 (2.0) versus 43.3 (3.1) 1/min, and ventilatory equivalent for oxygen (VE/ $\left.\dot{V} \mathrm{O}_{2}\right) 32.4$ (0.6) versus 38.7 (1.7). Age, sex, oxygen saturation and Burkholderia cepacia colonisation were not found to be significant predictors of mortality. When significant independent factors were entered into a multivariate logistic regression model only $\mathrm{FEV}_{1}$ was found to be a significant correlate of mortality. A cutoff for $\mathrm{FEV}_{1}$ of $55 \%$ predicted gave the best combination of specificity and sensitivity with $54 \%$ of those below this value dying within five years and $96 \%$ of those above it surviving.

Conclusions - The results of maximal exercise testing are correlated with survival but they are not better than the $\mathrm{FEV}_{1}$ as prognostic indicators.

(Thorax 1997;52:291-293)

Bradbury Adult Cystic

Fibrosis Unit,

Wythenshawe

Hospital, Southmoor

Road, Wythenshawe,

Manchester M23 9LT,

UK

A J Moorcroft

$M$ E Dodd

A K Webb

Correspondence to:

Dr A J Moorcroft.

Received 4 December 1995

Returned to authors

29 March 1996

Revised version received

27 September 1996

Accepted for publication

4 October 1996 Keywords: prognosis, exercise capacity, cystic fibrosis.

The life expectancy of patients with cystic fibrosis continues to improve with median survival now extending into the third decade of life. ${ }^{1}$ Most deaths, however, still occur in early adulthood from pulmonary disease. ${ }^{12}$ Assessment of prognosis is important in the management of individual patients and, in particular, when considering referral for lung transplantation. Many factors including sex, ${ }^{134}$ nutritional sta- tus, ${ }^{35}$ arterial $\mathrm{PCO}_{2},{ }^{46}$ Burkholderia cepacia colonisation, ${ }^{78}$ and spirometric values ${ }^{467}$ have been found to correlate with survival in cystic fibrosis. In a study of 673 patients Kerem et $a l^{4}$ found the forced expiratory volume in one second $\left(\mathrm{FEV}_{1}\right)$ to be the most significant predictor, and that patients with an $\mathrm{FEV}_{1}$ of less than $30 \%$ predicted had a $50 \%$ chance of dying within two years.

The value of exercise testing in the assessment of prognosis in cystic fibrosis has been studied infrequently. ${ }^{679}$ Patients attending the adult cystic fibrosis unit in Manchester over the last decade have undergone routine maximal exercise testing and we have investigated its prognostic value in comparison with previously described correlates of survival. This information may provide additional guidance in the assessment of prognosis in adults with cystic fibrosis.

\section{Methods}

The results of 92 patients who underwent exercise testing between 1986 and 1989 in whom the outcome at five years was known were retrospectively examined. Progressive incremental exercise testing to a symptom limited maximum was performed using an electronically braked cycle ergometer (Corival 300 , Gould, The Netherlands). The work rate was increased each minute in either 15 or 25 watt increments depending on the operator's assessment of fitness and disease severity. Measurements taken included minute ventilation (VE), oxygen uptake ( $\dot{V}_{2}$, Oxylog, P K Morgan, UK), work rate (W), oxygen saturation $\left(\mathrm{SaO}_{2}\right.$; Ohmeda Biox 7300a), and heart rate (Hr; S and W, Denmark). Peak values were taken at the end of the last minute of exercise. Age, sex, height, weight, and spirometric values (Vitalograph, Buckingham, UK) were recorded at baseline. Patient acquisition of $B$ cepacia during the five year period was noted, and the outcome in terms of survival was assessed at five years.

Body mass index (BMI) was calculated as weight in kilograms divided by the square of height in metres. $\mathrm{FEV}_{1}$ was expressed as a percentage of predicted normal values. ${ }^{10}$ Values of $\dot{\mathrm{VO}}_{2}$ peak and Wpeak were expressed as a percentage of predicted normal values calculated from age, sex, weight, and height. ${ }^{11}$ The ventilatory equivalent for oxygen $\left(\mathrm{VE} / \mathrm{Vo}_{2}\right)$ was calculated as $\dot{V}$ Epeak $/ \mathrm{VO}_{2}$ peak.

\section{STATISTICAL ANALYSIS}

The relationships between measured variables were explored using Pearson correlation. To 
Table 1 Comparison of group mean values at baseline testing between deaths and survivors

\begin{tabular}{lllcr}
\hline & $\begin{array}{l}\text { Deaths } \\
(n=22)\end{array}$ & $\begin{array}{l}\text { Survivors } \\
(n=65)\end{array}$ & $\begin{array}{l}\text { Mean difference } \\
\text { (confidence limits) }\end{array}$ & $p$ value \\
\hline $\mathrm{FEV}_{1}(\%$ pred) & 39.7 & 68.9 & $29.2(20.4$ to 38.0$)$ & $<0.001$ \\
$\mathrm{BMI}\left(\mathrm{kg} / \mathrm{m}^{2}\right)$ & 17.1 & 19.0 & $1.9(0.8$ to 2.9$)$ & 0.001 \\
$\mathrm{VO}_{2}$ peak $(\%$ pred) & 53.7 & 66.6 & $12.9(4.2$ to 21.5$)$ & 0.022 \\
$\mathrm{Wpeak}_{\mathrm{V}}(\% \mathrm{pred})$ & 71.3 & 89.4 & $18.1(3.6$ to 32.6$)$ & 0.015 \\
$\mathrm{VE} / \mathrm{Vo} \mathrm{o}_{2}$ & 38.7 & 32.4 & $-6.3(-9.9$ to -2.7$)$ & 0.002 \\
$\mathrm{VEpeak}(1 / \mathrm{min})$ & 43.2 & 51.3 & $8.1(0.3$ to 15.8$)$ & 0.04 \\
$\mathrm{SaO}_{2}$ rest $(\%)$ & 92.9 & 95.0 & $2.1(-0.5$ to 4.8$)$ & 0.12 \\
$\mathrm{Sa}_{2}$ peak $(\%)$ & 89.0 & 91.0 & $2.0(-0.7$ to 4.8$)$ & 0.14 \\
Age (years) & 20.2 & 19.7 & $-0.5(-3.0$ to 2.5$)$ & 0.66 \\
\hline
\end{tabular}

$\mathrm{FEV}_{1}=$ forced expiratory volume in one second; $\mathrm{BMI}=$ body mass index; $\mathrm{Vo}_{2}$ peak $=$ peak oxygen uptake; Wpeak = peak work rate; $\mathrm{VE} / \mathrm{VO}_{2}=$ ventilatory equivalent for oxygen; $\mathrm{SaO}_{2}=$ oxygen saturation.

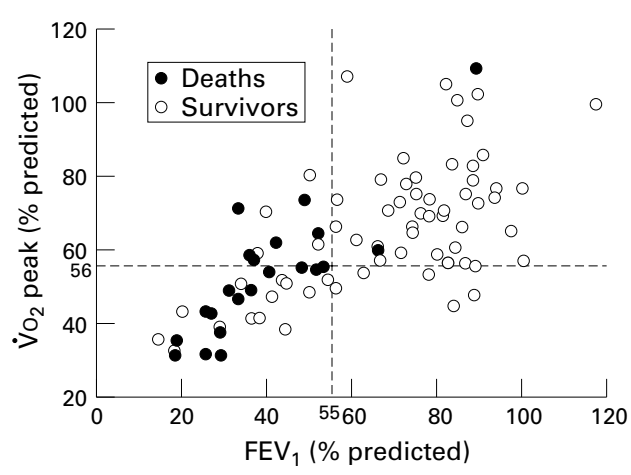

Figure 1 Relationship between $\mathrm{FEV}_{1}, \dot{\mathrm{V}} \mathrm{O}_{2}$ peak, and the outcome at five years. The $F E V_{1}$ was a better indicator of prognosis with a cut-off value of $55 \%$ predicted giving a sensitivity of $91 \%$ and a specificity of $74 \%$. The $\mathrm{VO}_{2}$ peak was a less good predictor with a sensitivity of $64 \%$ at a similar specificity of $72 \%$ when a cut-off value of $56 \%$ predicted was chosen. The correlation between FEV $V_{1}$ and ${ }_{\mathrm{V}_{2}}$ peak is also shown $(r=0.68, p<0.001)$.

entered into a multivariate logistic regress model as continuous variables to determine their relative significance. To allow an assessment of the specificity and sensitivity a variety of cut-offs were chosen and compared. A two tailed $p$ value of $<0.05$ was taken to indicate statistical significance.

\section{Results}

Data were available for 92 adult patients who had undergone maximal exercise testing and in whom outcome at five years was known. Five patients received lung transplants and were excluded from further analysis. Of the remaining 87 patients 35 were women and 24 had $B$ cepacia cultured from their sputum during the five years after testing. The mean age was 19.8 years (range $15-40$ ), the mean BMI was $18.5 \mathrm{~kg} / \mathrm{m}^{2}$ (range 13-27), and the mean $\mathrm{FEV}_{1}$ was $61.5 \%$ predicted (range 15-117).

There were 22 deaths during the five year follow up period. Table 1 shows the comparisons between deaths and survivors for age, BMI, spirometric values, and exercise data. The patients who died had a significantly lower mean $\mathrm{FEV}_{1}$ and BMI. On exercise testing they had a significantly lower $\mathrm{VO}_{2}$ peak, Wpeak, and VEpeak. $\dot{\mathrm{VE}} / \mathrm{V}_{2}$ was significantly higher in those who died, consistent with a larger physiological dead space. There were no significant differences between those who died and the survivors in the proportion of women $(41 \%$ versus $40 \%$ ) or the prevalence of $B$ cepacia ( $41 \%$ versus $23 \%$ ).

To assess the relative contributions of the different predictors of mortality, significant independent factors were entered into a multivariate logistic regression model as continuous variables. The $\mathrm{FEV}_{1}$ was found to be the most significant predictor of mortality. Other factors did not reach the 0.05 level of significance and, if forced into the model, added nothing to the predictive value.

For each $1 \%$ decrease in $\mathrm{FEV}_{1}$ the risk of dying within five years increased by $6.3 \%$ (confidence limits $3.3 \%$ to $9.2 \%$ ). Sensitivity and specificity of $\mathrm{FEV}_{1}$ were examined at a variety of cut-off values. A value of $55 \%$ gave the best combination, correctly identifying 20 out of 22 deaths $(91 \%)$ and 48 out of 65 survivors $(74 \%)$.
This also gave a positive predictive value of $54 \%(20 / 37)$ and a negative predictive value of $96 \%$ (48/50). By comparison, the optimal cutoff point of $\mathrm{VO}_{2}$ peak $(56 \%)$ correctly identified only 14 of 22 deaths $(64 \%)$ and 47 of 65 survivors $(72 \%)$. Figure 1 illustrates the relative value of $\mathrm{FEV}_{1}$ and $\mathrm{Vo}_{2}$ peak in the assessment of prognosis and also their relationship with each other.

There are relationships between the measured variables. $\mathrm{VO}_{2}$ peak was correlated with $\mathrm{FEV}_{1}(r=0.68 ; \mathrm{p}<0.001)$ and BMI $(r=0.36$; $\mathrm{p}<0.001) . \mathrm{FEV}_{1}$ was also correlated with BMI $(r=0.43 ; \quad \mathrm{p}<0.001), \quad$ VEpeak $\quad(r=0.53$; $\mathrm{p}<0.001)$ and $\dot{\mathrm{VE}} / \mathrm{Vo}_{2}(r=-0.47 ; \mathrm{p}<0.001)$. Wpeak was closely correlated with $\mathrm{VO}_{2}$ peak $(r=0.81 ; \mathrm{p}<0.001)$ and, when substituted for $\mathrm{VO}_{2}$ peak in the logistic regression models, made no difference to the results.

\section{Discussion}

The finding of a strong relationship between $\mathrm{FEV}_{1}, \mathrm{BMI}$, and mortality is consistent with previous studies. ${ }^{3458}$ Our data also show that the results of exercise testing have prognostic value with $\dot{\mathrm{VO}}_{2}$ peak, Wpeak, VEpeak, and $\dot{\mathrm{VE}}$ / $\mathrm{VO}_{2}$ all being significant predictors of mortality.

There have been very few studies concerning exercise testing and prediction of mortality in cystic fibrosis. In a study intended primarily to look at home oxygen therapy ${ }^{9}$ it was reported that, although the maximal work measured by cycle ergometry was related to survival, the maximal oxygen uptake was not. More recently, in an analysis of 67 patients accepted for heartlung transplantation, ${ }^{6}$ the distance covered on a 12 minute walk test did not predict survival. The most consistent prognostic indicators were found to be $\mathrm{FEV}_{1}$ and $\mathrm{PaCO}_{2}$. It should be noted, however, that the analysis did not differentiate between those who were transplanted and those for whom donor organs did not become available.

In the largest study of the prognostic value of exercise testing Nixon et $a l^{7}$ retrospectively examined survival at eight years in 109 patients 
who had undergone pulmonary function and exercise testing. Lower $\mathrm{FEV}_{1}$, sputum colonisation by $B$ cepacia, lower peak oxygen uptake, lower peak work capacity, higher end tidal $\mathrm{PCO}_{2}$ and lower $\mathrm{SaO}_{2}$ were associated with a significantly higher risk of dying. In a multivariate analysis only $\mathrm{Vo}_{2}$ peak, Wpeak, and sputum colonisation with $B$ cepacia were reported to be independent predictors of mortality. Our data similarly found $\mathrm{FEV}_{1}$, Wpeak and $\dot{\mathrm{VO}}_{2}$ peak to be related to prognosis but, in contrast, we found $\mathrm{FEV}_{1}$ to be the better predictor. The value of $\mathrm{FEV}_{1}$ in the prediction of mortality has been clearly described. ${ }^{467}$ It seems reasonable that $\mathrm{FEV}_{1}$ should be a good determinant of prognosis as most deaths occur from respiratory disease ${ }^{13}$ and the $\mathrm{FEV}_{1}$ is a good marker of pulmonary disease severity. Exercise performance is determined not only by pulmonary function, but will be influenced by many other factors including motivation, muscle mass, and conditioning. Peak performance therefore might not correlate as closely with the ultimate cause of death namely, respiratory failure. Our data confirm previous findings ${ }^{1213}$ of a strong relationship between pulmonary function and $\mathrm{VO}_{2}$ peak and it is therefore not surprising that both are related to prognosis.

With regard to the assessment of prognosis, $\dot{\mathrm{VE}} / \dot{\mathrm{V}}_{2}$ was a stronger predictor of mortality than $\dot{V O}_{2}$ peak but was closely correlated with $\mathrm{FEV}_{1}$ and did not better it as an indicator of prognosis. BMI was a good discriminator of outcome but, although better than $\dot{\mathrm{VO}}_{2}$ peak, was less good a predictor than $\mathrm{FEV}_{1}$ and again added nothing to its prognostic value.

Sex was not a prognostic factor in our population of adults. Whilst several authors have previously found female sex to be an adverse factor, ${ }^{134}$ their data have, in the main part, been based on survival rates in childhood. The situation in adulthood is less clear. Huang et $a \bar{l}$ reported a high early mortality rate among women but found no sex difference in survival for those who lived beyond 18 years. Similarly, the British Paediatric Working Party on Cystic Fibrosis ${ }^{14}$ commented that "beyond age 20 there seems to be a reversal of the earlier trend to higher female mortality".
The culture of $B$ cepacia from sputum was not found to be an adverse prognostic factor in this population although there was a nonsignificant excess of deaths found amongst those colonised. This lack of statistical significance might be due to the analysis not taking the length of colonisation into account and therefore being less sensitive to a time-dependent effect.

A review of the prognostic value of exercise testing such as this should not be confused with the question of the role of exercise training in maintaining health and function. Data from short term studies ${ }^{15}$ suggest that exercise is a valuable component of cystic fibrosis care. With regard to exercise testing and the assessment of prognosis, however, we must conclude that, whilst peak oxygen uptake, work, ventilation and ventilatory equivalent are correlates of survival, they are not better than $\mathrm{FEV}_{1}$ as prognostic indicators.

1 Fitzsimmons SC. The changing epidemiology of cystic fibrosis. F Pediatr 1993;122:1-9.

2 Penketh ARL, Wise A, Mearns MB, Hodson ME, Batten JC. Cystic fibrosis in adolescents and adults. Thorax 1987; 42:526-32

3 Corey M, McLaughlin FJ, Williams M, Levison H. A comparison of survival, growth and pulmonary function in patients with cystic fibrosis in Boston and Toronto. $\mathcal{F}$ Clin Epidemiol 1988;41:583-91

4 Kerem E, Reisman J, Corey M, Canny GJ, Levison H Prediction of mortality in patients with cystic fibrosis. $N$ Engl f Med 1992;326:1187-91.

5 Huang NN, Schidlow DV, Szatrowski TH, Palmer J, LarayaCuasay LR, Yeung W, et al. Clinical features, survival rate and prognostic factors in young adults with cystic fibrosis. Am $\mathcal{F}$ Med 1987;85:871-7.

6 Sharples L, Hathaway T, Dennis C, Caine N, Higenbottam T, Wallwork J. Prognosis of patients with cystic fibrosis awaiting heart and lung transplantation. F Heart Lung Transplant 1993;12:669-74

7 Nixon PA, Orenstein DM, Kelsey SF, Doershuk CF. The prognostic value of exercise testing in patients with cystic fibrosis. $N$ Engl f Med 1992;327:1785-8.

8 Lewin LO, Byard PJ, Davies BD. Effect of Pseudomona cepacia colonisation on survival and pulmonary function of cystic fibrosis patients. F Clin Epidemiol 1990;43;125-31.

9 Zinman R, Corey M, Coates AL, Canny GJ, Connolly J, Levison $\mathrm{H}$, et al. Nocturnal home oxygen in the treatmen of hypoxaemic cystic fibrosis patients. $\mathcal{\exists}$ Pediatr $1989 ; 114$ 368-77.

10 Knudson RJ, Lebowitz MD, Hollberg CJ, Burrows B. Changes in the normal maximum expiratory flow-volume curve with growth and ageing. Am Rev Respir Dis 1983 127:725-34.

11 Jones NL. Clinical exercise testing. 3rd edn. Philadelphia: WB Saunders, 1988

12 Godfrey S, Mearns M. Pulmonary function and response to exercise in cystic fibrosis. Arch Dis Child 1971;46: $144-51$

13 Marcotte JE, Grisdale BA, Levison H, Coates AL, Canny GJ. Multiple factors limit exercise capacity in cystic fibrosis. Pediatr Pulmonol 1986;2:274-81.

14 British Paediatric Working Party on CF. Cystic fibrosis in the United Kingdom 1977-85: an improving picture. $B M F$ 1988;297:1599-602

15 Webb AK, Dodd ME, Moorcroft J. Exercise and cystic fibrosis. F $R$ Soc Med 1995;88:30-6. 